\title{
Pengaruh Body Dysmorphix Dysorder pada Self Esteem Mahasiswa
}

\author{
Ch.Erghiezha Ninuk Indrati $\mathrm{K}^{1}$, Eka Apriliana ${ }^{2}$ \\ Universitas Kanjuruhan Malang \\ erghiezha@gmail.com¹, Echkaapriel14@gmail.com²
}

\begin{abstract}
Abstrak
Self Esteem merupakan evaluasi yang dibuat individu kebiasaan memandang dirinya terutama mengenai sikap menerima atau menolak, dan indikasi besarnya kepercayaan individu terhadap kemampuannya, keberartian, kesuksesan dan keberhargaan. Faktor yang dianggap memiliki peran penting _dalam berkembangnya Body Dysmorphic Disorder adalah Self-esteem. Metode penelitian ini korelasional. sampel dalam penelitian ini 67 dengan metode pengambilan sampel purposive sampling, Pengambilan data dengan instrument self esteem dan instrument Body Dysmorphic Disorder. Hasil analis data menggunakan product momen dengan hasil $\mathrm{r}$ hitung $-0,528>0,339$ berarti ada pengaruh negative yang signifikan body dysmorphix disorder pada self esteem. Bahwa body dysmorphic disorder dapat mempengaruhi self esteem dalam taraf sedang.
\end{abstract}

Kata Kunci : self esteem,body dysmorphic disorder

\section{Abstract}

Self esteem is an evaluation made by the individual and the habit of viewing himself especially about the attitude of accepting or rejecting and an indication of the magnitude of individual confident in their abilities meanings success and rewards. Factor considered to have an important rate in the development of body dysmorphic disorder are self esteem. The correlational research method, example in research 67 study with purposive sampling method. Data collection with sel esteem instrument and body dysmorphic disorder instrument. The result of data analysis produc moment with the result $r$ arithmetic - 0,528 $>0,339$. Means there is a negative influence significant body dysmorphic disorder in self esteem. That body dysmorphic disorder can affect self esteem in a moderate level.

Keyword: self esteem, body dysmorphic disorder

\section{PEDAHULUAN}

Bagi remaja fisik merupakan aspek penting dalam menjalani semua aktivitasnya, karena yang menjadi pedoman kesempurnaan remaja adalah penampilan bentuk tubuhnya. Perubahan dalam sikap dan perilaku selama masa remaja sejajar dengan tingkat perubahan fisik. Selama masa remaja perubahan fisik terjadi sangat pesat, sehingga perilaku dan sikap juga berlangsung sangat pesat. Remaja yang mengalami perubahan fisik menurun, maka perubahan sikap dan perilaku juga ikut menurun juga. Beberapa remaja menginginkan penampilan tubuhnya terlihat sempurna. Kebanyakan remaja menyadari bahwa mereka yang tampil meanarik biasanya lebih dihargai daripada mereka yang kurang menarik.

Kenyataan yang terjadi pada remaja adalah emosi yang labil akibat dari perkembangan hormon yang berkembang sangat pesat pada tubuh remaja. Seiring dengan zaman yang semakin modern ini, remaja sekarang sudah merasakan dan mengerti tentang gengsi. Banyak remaja yang tidak bisa menerima keadaan tubuhnya, sehingga remaja cenderung menutupi kekurangannya dengan cara apapun.

Fakta yang terjadi dilapangan berdasarkan pengamatan peneliti pada Mahasiswa Universitas Kanjuruhan Malang yaitu kebanyakan remaja bersaing 
untuk tampil cantik dan tampan. Beberapa remaja ada yang bangga dengan keadaan tubuh yang dimiliknya, dan beberapa yang cenderung tidak nyaman dengan keadaan tubuhnya. Salah satu contoh ada seorang remaja perempuan dengan bentuk giginya maju kedepan, sehingga dengan membuatnya terlihat tidak maju kedepan, siswa tersebut memasang behel digiginya, tetapi setelah remaja tersebut memasang behel di giginya dia masih tidak bisa percaya diri.

Hasil penelitian dari Merlina (2016) terdapat pengaruh citra tubuh terhadap Body Dysmorphic Disorder (BDD) yang dimediasi oleh harga diri (self-esteem). Artinya jika remaja putri tidak puas dengan bentuk tubuhnya maka citra tubuh yang muncul adalah negatif yang akan mempengaruhi harga diri remaja menjadi rendah sehingga membuat remaja putri dapat mengarah kepada gejala body dysmorphic disorder (BDD). Hasil penelitian dari Rahmanai (2012) membuktikan bahwa usia remaja merupakan usia terdapat hubungan yang signifikan antara self-esteem dengan kecenderungan body dysmorphic disorder pada remaja putri. Kedua variabel memiliki hubungan negatif yang menggambarkan bahwa semakin tinggi self-esteem maka semakin rendah kecenderungan body dysmorphic disorder dan sebaliknya, semakin rendah selfesteem maka semakin tinggi kecenderungan body dysmorphic disorder.
Penelitian yang dilakukan Mirza \& Davis (2005) pada 113 anak dan remaja di El-savadoran American menyebutkan bahwa tingginya body max indexs berhubungan dengan ketidakpuasan terhadap tubuh, rendahnya harga diri dan usaha untuk mengurangi berat badan. Ketidakpuasan terhadap tubuh memiliki signifikasi dengan harga diri. Pengamatan peneliti pada Mahasiswa Universitas Kanjuruhan Malang, kebanyakan remaja mengalami kecemasan penampilan fisik dan harga diri rendah. Berangkat dari hal ini, peneliti ingin mengetahui secara dalam, sehingga peneliti tertarik untuk meneliti masalah tersebut yang diberi judul "H Pengaruh Body Dysmorphic Disorder (BDD) pada Self-esteem Mahasiswa Universitas Kanjuruhan Malang"

\section{METODE PENELITIAN}

Jenis penelitian ini adalah penelitian korelasi merupakan penelitian yang dimaksudkan untuk mengetahui ada tidaknya pengaruh antar dua variabel. Dalam penelitian ini terdapat dua variabel yang diteliti variabel bebas (X) adalah Body Dysmorphic Disorder dan variabel terikat (Y) adalah Self Esteem.

Dengan jumlah populasi pe nelitian 67 mahasiswa yang memakai behel. Karena jumlah populasinya kurang dari 100 orang maka keseluruhan populasi dipergunakan sebagai sampel, jadi dalam penelitian ini menggunakan sampling jenuh adalah sampel yang mewakili jumlah populasi. Untuk menentukan analisis data 
menggunakan korelasi produk momen. Hasil akhir dari perhitungan ini akan menunjukkan kuat tidaknya pengaruh variabel X pada Variabel Y. Adapun mengenai kuat tidaknya suatu pengaruh atau hubungan dapat dilihat dari besar kecilnya angka yang dihasilkan. Langkah selanjutnya yang dilakukan adalah pengujian hipotesis.

Tabel Klasifikasi Koefisien Guilford, Sumber: Sugiyono (2004)

\begin{tabular}{|c|c|c|}
\hline No & $\begin{array}{c}\text { Interval } \\
\text { Koefisien }\end{array}$ & Klasifikasi \\
\hline 1. & $0.000-0.199$ & $\begin{array}{c}\text { Sangat rendah / } \\
\text { Lemah }\end{array}$ \\
\hline 2. & $0.200-0.399$ & Rendah \\
\hline 3. & $0.400-0.599$ & Sedang \\
\hline 4. & $0.600-0.799$ & Tinggi / Kuat \\
\hline 5. & $0.800-1.000$ & $\begin{array}{c}\text { Sangat Tinggi / } \\
\text { Sangat Kuat }\end{array}$ \\
\hline
\end{tabular}

\section{Hasil}

1) Deskripsi data Body dysmorphic Disorder

Tabel Distribusi Frekuensi Body dysmorphic disorder

\begin{tabular}{|l|c|c|c|}
\hline $\begin{array}{c}\text { Body } \\
\text { dysmorphic } \\
\text { disorder }\end{array}$ & Frek- & Persen- & Interprestasi \\
tase & \\
\hline Pikiran & 16 & 23,8 & Sedikit \\
$\%$ & 34 & $50,7 \%$ & Cukup \\
\hline Perasaan & & & \\
\hline
\end{tabular}

\begin{tabular}{|l|c|c|c|}
\hline Perilaku & 13 & $19,4 \%$ & $\begin{array}{l}\text { Sangat } \\
\text { Sedikit }\end{array}$ \\
\hline Hubungan & 4 & 5,9 & Sangat \\
Sosial & & $\%$ & Sedikit \\
\hline
\end{tabular}

Pada tabel di atas terlihat mahasiswa yang memiliki aspek pikiran yaitu 16 mahasiswa yang memiliki persentase Body dysmorphic disorder sebesar 23,8\%, Pada persentase sapek perasaan yaitu 34 mahasiswa dan merupakan jumlah terbanyak yang memiliki persentase Body dysmorphic disorder sebesar 50,7\%, Pada persentase aspek perilaku yaitu 13 mahasiswa yang memiliki persentase Body dysmorphic disorder sebesar 19,4\%, dan persentase aspek Hubungan sosial yaitu 4 mahasiswa yang memiliki persentase Body dysmorphic disorder sebesar 5,9\%. Lebih jelasnya digambarkan pada diagram batang dibawah ini:

\section{Gambar. Gambaran umum body}

dysmorphic disorder

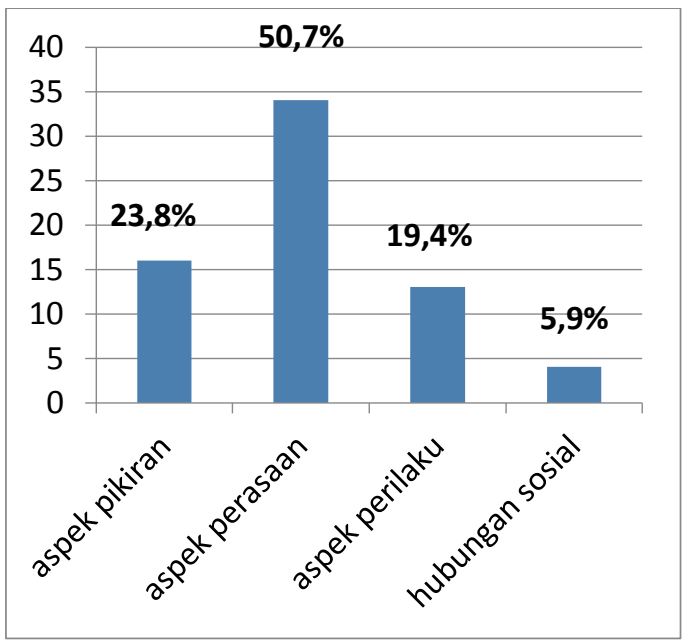


1) Deskripsi Self esteem

Tabel Distribusi Frekuensi

Self esteem

\begin{tabular}{|l|c|c|c|}
\hline Self esteem & $\begin{array}{c}\text { Frek } \\
\text { uensi }\end{array}$ & $\begin{array}{c}\text { Persen } \\
\text { tase }\end{array}$ & Persentase \\
\hline Kekuasaan & 21 & $31,3 \%$ & Sedikit \\
\hline Keberartian & 38 & $56,7 \%$ & Cukup \\
\hline Kebajikan & 5 & $7,4 \%$ & $\begin{array}{c}\text { Sangat } \\
\text { Sedikit }\end{array}$ \\
\hline Kemampuan & 3 & $4,4 \%$ & $\begin{array}{c}\text { Sangat } \\
\text { Sedikit }\end{array}$ \\
\hline \multicolumn{4}{|c|}{ Pada tabel di } \\
\hline
\end{tabular}

mahasiswa yang memiliki aspek

kekuasaan yaitu 21 mahasiswa yang memiliki persentase Self esteem sebesar $31,3 \%$, Pada persentase apek keberartian yaitu 38 mahasiswa dan merupakan jumlah terbanyak yang memiliki persentase Self esteem sebesar 56,7\%, Pada persentase aspek kebajukan yaitu 5 mahasiswa yang memiliki persentase Self eteem sebesar $7,4 \%$, dan persentase aspek kemampuan yaitu 3 mahasiswa yang memiliki persentase Body dysmorphic disorder sebesar 4,4\%. Lebih jelasnya digambarkan pada diagram batang dibawah ini:

Gambar. Gambaran umum Self eteem

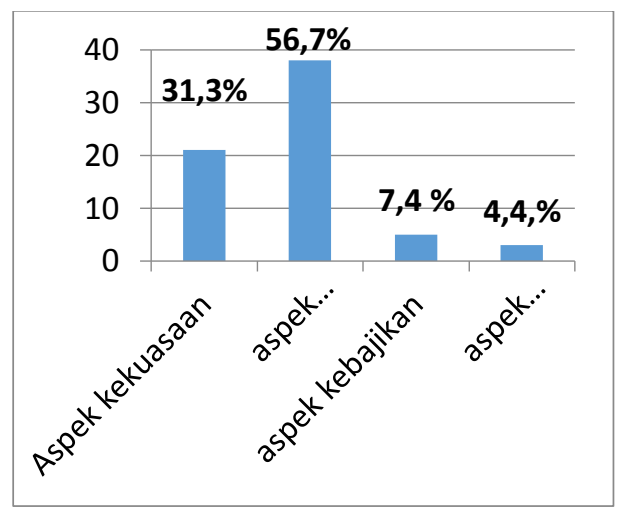

1) Mean dan Standard Deviasi

Tabel Hasil perhitungan mean dan Standard Deviasi

Descriptive Statistics

\begin{tabular}{|l|l|l|r|}
\hline \multicolumn{1}{|c|}{ Variabel } & & & \multicolumn{2}{c|}{$\begin{array}{c}\text { Std. } \\
\text { Deviation }\end{array}$} \\
& N & Mean & 2.605 \\
aspek_pikiran & 67 & 11.94 & 2.829 \\
aspek_perasaan & 67 & 11.70 & 2.894 \\
aspek_perilaku & 67 & 13.52 & 7.317 \\
hubungan_sosial & 67 & 34.03 & \\
Valid N (listwise) & 67 & & \\
\hline
\end{tabular}

Berdasarkan tabel diketahui mean atau nilai rata-rata dari Body dysmorphic disorder Pikiran, perasaan, perilaku dan hubungan sosial adalah $(11.94, \quad 11.70, \quad 13.52, \quad 34.03)$ yang kemudian digunakan untuk mengetahui standar deviasi.

1) Hasil Analisis Korelasi

Dalam pengujian hipotesis yang harus diuji adalah:

$$
\begin{gathered}
r_{x y}= \\
\frac{n \Sigma X Y-(\Sigma X)(\Sigma Y)}{\sqrt{\left\{\left(n \Sigma X^{2}-(\Sigma X)^{2}\right\}\left\{n \Sigma Y^{2}-(\Sigma Y)^{2}\right\}\right.}}
\end{gathered}
$$

Keterangan:

$r_{x y}$ : Koefisien korelasi antara X dan Y

$Y \quad$ : Skor Total

N : Jumlah Subyek

(Arikunto, 2012:146). Dalam penelitian ini analisis korelasi dihitung menggunakan program SPSS for Windows. Berikut contoh perhitungan korelasi antara Body Dysmorphic disorder dan Self esteem. 
Diketahui:

$\Sigma Y \quad: 5849$

$\Sigma \mathrm{X}: 4770$

$\mathrm{N}: 67$

$\Sigma Y^{2} \quad: 517959$

$\Sigma X^{2}: 349258$

$\Sigma X Y \quad: 411961$

$r_{x y}=\frac{n \Sigma X Y-(\Sigma X)(\Sigma Y)}{\sqrt{\left\{\left(n \Sigma X^{2}-(\Sigma X)^{2}\right\}\left\{n \Sigma Y^{2}-(\Sigma Y)^{2}\right\}\right.}}$

$=\frac{67.411961-(4770)(5849)}{\sqrt{\left\{\left(67.349258-(4770)^{2}\right\}\left\{67.517959-(5849)^{2}\right\}\right.}}$

$=\frac{-298343}{\sqrt{(647386)(492452)}}$

$=\frac{-298343}{(804,6)(701,7)}$

$=\frac{-298343}{56458782}$

$=-0,528$

Pada perhitungan diatas

diperoleh nilai korelasi atau $r_{\text {hitung }}$ sebesar

$-0,528$ hal ini menunjukkan bahwa $r_{\text {hitung }}$ $>\mathrm{r}_{\text {tabel }}(-0,528>0,339)$, berarti ada hubungan negatif yang signifikan antara Body Dysmorphic Disorder dan Self Esteem. Nilai tersebut dapat diklasifikasikan memiliki hubungan yang termasuk dalam kategori sedang.

\section{PEMBAHASAN}

\section{A. Body Dysmorphic disorder}

Hasil penelitian menunjukkan bahwa dari beberapa mahasiswa Universitas Kanjuruhan Malang, terdapat 16 mahasiswa yang memiliki kecenderungan Body dysmorphic disorder aspek pikiran sebesar $23.8 \%$, 34 mahasiswa yang memiliki kecenderungan Body dysmorphic disorder aspek perasaan sebesar 50.7 $\%, 13$ mahasiswa yang memiliki kecenderungan Body dysmorphic disorder aspek perilaku sebesar 19.4\%, 4 mahasiswa yang memiliki kecenderungan Body dysmorphic disorder Hubungan sosial sebesar $5.9 \%$.

Menurut Rosen menyatakan bahwa Body Dysmorphic Disorder (BDD) dapat diklasifikasikan kedalam empat aspek yang membentuk psikodinamika yaitu: Aspek Pikiran, aspek perasaan, aspek perilaku, dan hubungan sosial.

Hasil penelitian menunjukkan bahwa dari beberapa mahasiswa Universitas Kanjuruhan Malang memiliki Body dysmorphic disorder yang beragam akan tetapi Body dysmorphic disorder yang terlihat konsisten dan dominan adalah Body dysmorphic disorder aspek perasaan sejumlah 34 mahasiswa sebesar 50.7\%.

\section{Body Dysmorphic disorder aspek}

\section{Pikiran}

Jumlah mahasiswa Universitas Kanjuruhan Malang hasil penelitian menunjukkan bahwa yang memiliki Body Dysmorphic disorder aspek Pikiran adalah 16 mahasiswa sebesar $23.8 \%$. Perasaan yang negatif pada tubuh akan berfikiran untuk menutupi kekurangan tubuh yang dianggap 
membuat individu itu tidak percaya diri.

\section{Body Dysmorphic disorder aspek Perasaan}

Jumlah mahasiswa Universitas Kanjuruhan Malang hasil penelitian menunjukkan bahwa yang memiliki Body Dysmorphic disorder aspek Perasaan adalah 34 mahasiswa sebesar $50.7 \%$. Mahasiswa yang memiliki Body Dysmorphic disorder akan menilai secara negatif bentuk tubuhnya baik secara keseluruhan maupun bagian dari tubuhnya.

\section{Body Dysmorphicdisorder aspek} Perilaku

Jumlah mahasiswa Universitas Kanjuruhan Malang hasil penelitian menunjukkan bahwa yang memiliki Body Dysmorphic disorder aspek Perilau adalah 13 mahasiswa sebesar 19.4\%. Kecemasan pada Body DSysmorphic disorder itu bersifat sementara dan akan memudar dengan sendirinya ketika mahasiswa dapat menanamkan rasa percaya diri pada dirinya sendiri melalui kegiatan dan rutinitas sehari-hari.

\section{Body Dysmorphic disorder} Hubungan sosial

Jumlah mahasiswa Universitas Knajuruhan Malang hasil penelitian menunjukkan bahwa yang memiliki Body Dysmorphic disorder Hubungan sosial adalah 4 mahasiswa sebesar
5.9\%. Mahasiswa yang mengalami Body Dysdmorphic disorder akan merasa malu dengan tubuh yang dianggap mengurangi kesempurnaan fisik yang ada pada tubuhnya. Mahasiswa akan memghindari orangorang disekitarnya dengan kurang bergaul dengan orang lain, sehingga komunikasi dengan orang disekitarnya akan menjadi penghindaran hubungan sosial.

\section{B. Self Esteem}

Hasil penelitian menunjukkan bahwa dari beberapa mahasiswa Universitas Kanjuruhan Malang, terdapat 21 mahasiswa yang memiliki Self esteem aspek kekuasaan sebesar 31.3\%, 38 mahasiswa yang memiliki Self esteem aspek keberartian sebesar $56.7 \%$, 5 mahasiswa yang memiliki Self esteem aspek kebajikan sebesar 7.4\%, 3 mahasiswa yang memiliki Self esteem aspek kemampuan sebesar $4.4 \%$.

Menurut Coopersmith (1967: 3844) ada beberapa komponen yaitu: aspek kekuasaan, aspek keberartian, aspek kebajikan, dan aspek kemapuan.

Hasil penelitian menunjukkan bahwa dari beberapa mahasiswa Universitas Kanjuruhan Malang memiliki Self esteem yang terlihat konsisten dan dominan adalah Self esteem aspek Keberartian sejumlah 38 mahasiswa sebesar $56.7 \%$. 


\section{Hubungan Body dysmorphic disorder} aspek Pikiran dengan Self esteem

Hasil penelitian menunjukkan bahwa nilai signifikansi $0.001<0.05$, dan $r_{\text {hitung }}(-0.217)>r_{\text {tabel }}(0.240)$, oleh karena itu H0 ditolak dan Hi diterima. Artinya ada hubungan negatif yang signifikan (-0.217) antara variabel Body Dysmorphic disorder aspek Pikiran dengan Self esteem. Kesimpulannya adalah semakin tinggi Body Dysmorphic disorder aspek Pikiran maka Self esteem mahasiswa akan semakin rendah.

\section{Hubungan Body dysmorphic disorder} aspek Perasaan dengan Self esteem

Hasil penelitian menunjukkan bahwa nilai signifikansi $0.001<0.05$, dan $r_{\text {hitung }}(-0.415)>r_{\text {tabel }}(0.240)$, oleh karena itu H0 ditolak dan Hi diterima. Artinya ada hubungan negatif yang signifikan (-0.415) antara variabel Body Dysmorphic disorder aspek Perasaan dengan Self esteem. Kesimpulannya adalah semakin tinggi Body Dysmorphic disorder aspek Perasaan, maka Self esteem mahasiswa akan semakin rendah.

\section{E. Hubungan Body dysmorphic disorder} aspek Perilaku dengan Self esteem

Hasil penelitian menunjukkan bahwa nilai signifikansi $0.022<0.05$, dan $r_{\text {hitung }}(-0.279)>r_{\text {tabel }}(0.240)$, oleh karena itu H0 ditolak dan Hi diterima. Artinya ada hubungan negatif yang signifikan (-0.279) antara variabel Body Dysmorphic disorder aspek Perilaku dengan Self esteem. Kesimpulannya adalah semakin tinggi Body Dysmorphic disorder aspek Perilaku, maka Self esteem mahasiswa akan semakin rendah.

\section{F. Hubungan Body dysmorphic disorder} Hubungan Sosial dengan Self esteem Hasil penelitian menunjukkan bahwa nilai signifikansi $0.000<0.05$, dan $r_{\text {hitung }}(-0.526)>r_{\text {tabel }}(0.240)$, oleh karena itu H0 ditolak dan $\mathrm{Hi}$ diterima. Artinya ada hubungan negatif yang signifikan (-0.526) antara variabel Body Dysmorphic disorder Hubunag sosial dengan Self esteem. Kesimpulannya adalah semakin tinggi Body Dysmorphic disorder Hubungan sosial, maka Self esteem mahasiswa akan semakin rendah.

\section{PENUTUP}

Berdasarkan masalah penelitian, disimpulkan sebagai berikut:

Aspek Pikiran, Aspek Perasaan, Aspek Perilaku, dan Hubungan Sosial) Body dysmorphic disorder yang dominan adalah Aspek Perasaan . Self Esteem pada hasil penghitungan bahwa bisa disimpulkan bahwa 21 mahasiswa memiliki self esteem dengan kategori sangat tinggi atau sebesar $31.3 \%, 38$ mahasiswa memiliki tingkat self esteem kategori tinggi atau sebesar $56.7 \%$, 5 mahasiswa memiliki tingkat self esteem 
rendah atau sebesar $7.4 \%$, dan 3 mahasiswa memiliki tingkat self esteem sangat rendah atau sebesar $4.4 \%$

Ada pengaruh yang signifikan antara Body dysmorphic disorder dan Self esteem Mahasiswa Universitas Kanjuruhan Malang. Semakin tinggi Body dysmorphic disorder pada mahasiswa maka self esteem akan semakin rendah pula. Dan jika

\section{DAFTAR PUSTAKA}

American Psychiatric Association. (2000).

Diagnostic and statistical manual of mental disorders $(4$ th ed.. Washington, DC.

Anderson, R., Saulsman, L., McEvoy, P., Furshland, A., Nathan, P., \& Ridley, S. (2012).Building Body Acceptance: Overcoming Body Dysmorphic Disorder. Perth, Western Australia: Center for Clinical Interventions.

Arikunto.(2010).Prosedur

Penelitian:Suatu

Pendekatan

Praktek.Jakarta:Rineka Cipta.

Azwar, Saifuddin.(2010).Metode

Penelitian.Yogyakarta Pustaka

Pelajar.

Baron, R., \& Byrne, D. (2012). Psikologi

Sosial. Jakarta: Erlangga.

Budianti, AK. (2015). Hubungan antara

keharmonisan keluarga dengan harga

diri pada remaja. Universitas

Muhammadiyah Surakarta.

Carol E. Watkins. (2006). Body

Dysmorphic Disorder. Available at : semakin tinggi pula Self esteem maka Body dysmorphic disorder akan semakin rendah juga.

Saran penelitian adalah (1) Agar harga diri mahasiswa yang body dysmorphic tinggi sebaiknya memakai behel. (1) Untuk peneliti selanjutnya diharapkan menggunakan sampel yang lebih besar.

http://www.ncpamd.com/bodydysmor phicdisorder.

Coopersmith, Stanley. (1967). The Antecedents of Self Esteem.

Elliott, Gary. (2010). “Body Dysmorphic Disorder. A Male Concern". Honolulu, Hawai: Atlantic International University.

Esudu, Samson (2015)."Human Relations. Self esteem and Human Relations". Grin Verlag.

Greene, B, Nevid, JS,. Rathus. (2005). Psikologi Abnormal. Jakarta: Penerbit Erlangga.

J. Kevin Thompson. (2002).Body Image and Body dysmorphic Disorder. [online]

Lidenfield, Gael. (2014). Self esteem: Simple Steps to Build your Confidence.International BestSeller.

Mind."Body Dysmorphic Disorder". For better mental health.

Mirza, N.M., Davis, D., Yanovski, J.A. (2005). Body dissatisfaction, selfesteem, and overweight among innercity Hispanic children and adolescents. Journal of Adolescent Health, 36.267.e16-267.e.20. 
Oktario. (2008). Harga Diri Remaja Yatim Piatu. Universitas Sumatra Utara.

Philips, K.A., Pinto,A., Jain.S. (2004).SelfEsteem in body dysmorphic disorder.Body Image I. 385-390.

Philips, K.A. (2009). Understanding Body dysmorphic disorder: An essential guide. New York: Oxford University Press.

Pratiwi, Lulun Rosana. (2011). Hubungan Kebermaknaan Hidup dengan Self Esteem pada penghuni atau siswa pusat rehabilitas narkoba Rumah Damai. Universitas Negeri Semarang. Rahmania, \& Yuniar, I. (2012). Hubungan antara Harga diri dengan kecenderungan Body Dysmorphic Disorder pada Remaja Putri. Jurnal Psikologi Klinis dan Kesehatan Mental, I(2). 110-117.
Sugiyono.(2010). Metode Penelitian Kuantitatif Kualitatif \& RND. Bandung: Alfabeta.

Sugiyono, (2011). Metode Penelitian Pendidikan (Pendekatan Kuantitatif, Kualitatif, dan R\&D); Alfabeta. Bandung.

Tanzeh, Ahmad. (2009). Pengantar Metode penelitian. Yogyakarta: Teras. Tanzeh, Ahmad. (2011). Metodologi Penelitian Praktis. Yogyakarta: Teras. Veale (2001). "Cognitive-behavioural therapy for body dysmorphic disorder". Advances in Psychiatric Treatment 7: 125-132.

Veale \& Riley,S.(2001) Mirror, mirror on the wall, who is the ugliest of them all? The psychopathogy of mirror gazing in body dysmorphic disorder. Behaviour Research and Therapy (in press). 